\title{
Influential Factors upon Universities' Patent Application in China Jiangsu Province: Based on Structural Equation Model
}

\author{
Wei FANG* \\ School of Management, Northwestern Polytechnical University, \\ 1 Dongxiang Road, Chang'an District, Xi'an Shaanxi,710129, P.R.China. \\ E-mail: fwx1998@nwpu.edu.cn \\ Congchen LIN \\ School of Management, Northwestern Polytechnical University, \\ 1 Dongxiang Road, Chang'an District, Xi'an Shaanxi,710129, P.R.China. \\ E-mail: 1065224776@mail.nwpu.edu.cn \\ $\mathrm{Bu}$ YANG \\ School of Management, Northwestern Polytechnical University, \\ 1 Dongxiang Road, Chang'an District, Xi'an Shaanxi,710129, P.R.China. \\ E-mail: 857284668@qq.com \\ Ming KOU \\ School of Management, Northwestern Polytechnical University, \\ 1 Dongxiang Road, Chang'an District, Xi'an Shaanxi,710129, P.R.China. \\ E-mail: 1105900791@mail.nwpu.edu.cn
}

\begin{abstract}
Nowadays, independent intellectual property rights have become a powerful weapon for the national competition. Mass innovation is also one of the engines of economic development. China is accelerating the construction of an innovative country. As patents are an important part of independent intellectual property rights, research on patents is helpful to China's innovation construction. Ten factors affecting the higher institutions' patent application are summarized and extracted by carding literature. On this basis, three main factors including higher institutions' internal environment, social environment and cooperative environment which influence the ten factors are abstracted by utilizing the exploratory factor analysis. Then, this paper takes China Jiangsu province higher institutions as an example to construct the influential factors' routes model of higher institutions' patent application. Structural equation model is used to verify and modify the model based on the questionnaire data. The results show that the three types of environment have a positive effect on higher institutions' patent application, in which the higher institutions' internal environment has the most effect on the patent application. The higher institutions' internal environment and the social environment also have an effect on the cooperative environment, which also affects the patent application. Therefore, higher institutions and society are required to improve their internal environment and construct the favorable social environment of patent application respectively as well as the higher institutions and governments are required to create the cooperative environment that is beneficial for patent application so that they can promote the higher institutions' patent application.
\end{abstract}

Keywords: patent application; influential factors; influential route; structural equation model

DOI: $10.7176 / \mathrm{EJBM} / 12-9-01$

Publication date:March $31^{\text {st }} 2020$

\section{Introduction}

Since the 21st century, independent intellectual property has become an important strategic means of competition between countries and play an increasingly important role in the development of domestic economy[1]. To build an innovative country, we must strengthen China's capacity for independent innovation, vigorously cultivate the innovation capacity of universities, enterprises and research institutes, and make them have more independent intellectual property. Patents are one of the most important forms of intellectual property [2], it is great significance of improve China's overall innovation capability to study it.

As an important contributor to the increase of domestic patent applications, universities have accumulated the most abundant scientific and technological resources and made significant contributions to China's scientific and technological innovation and economic development. The quantity and quality of patents has always been an important criterion to measure the independent innovation ability of a university. Therefore, under the background of China's rapid growth of patent applications, discusses influence factors of universities apply patent and the influence of various factors on the application for a patent for the path to ensure or improve the patent filings and promote national continuous innovation is of great significance. 
Jiangsu province, as a major and strong province of education in China, has been leading the country in education results, and is no exception in terms of patents. According to a 2016 released by the ministry of education science and technology development center in 2015, before the invention patent grant 50 list of universities, and the end of 2015 top 50 list of universities by effective amount of a patent for invention, the invention of the universities in Jiangsu province to obtain patent grant and effective quantity of invention patent separately the provincial (city, area) the first, second. Therefore, this paper will select universities in Jiangsu province as the research object to explore the factors affecting its patent application and the influence of various factors on the patent application path, thus on the one hand, can put forward Suggestions for the improvement of patent applications in universities in Jiangsu province, on the other hand can also provide reference to other provincial universities, so as to promote national innovation.

\section{Correlational research}

2.1. Research methods on factors influencing the number of patent applications

Previous studies on the factors influencing the number of patent applications have mostly focused on the use of relevant statistical methods to study whether various factors have an impact on the number of patent applications. Zhang, Q. H. [3], using nonparametric statistical methods to study the Shanghai patent funding policy impact on patent applications, and found that the current funding policy of invention and utility model patent application has significant effect to the promotion number, number of applications for a patent for design of ascension has no obvious effect. Eduardo Fé. discuss parametric and nonparametric estimation of the model, and estimate a production function for the number of patents awarded to a firm given expenditure on R\&D [4]. Christian Fisch [5] Utilizing Cox regressions and compared with the United States, Europe, Japan, Korea. The relationship between the increase of patent application and the increase of patent value in China was studied, the results showed that: compared with the international, although Chinese patent applications increase faster, but low China patent value increase. But the gap between China and the rest of the world will narrow in the future.

Jianwei Dang [6] made a bibliometric analysis of patenting activities of Chinese large and medium-sized enterprises under local patent subsidy programs and test whether patent statistics are a good indicator of innovation in China. Fisch [7] analyzed the quantity and quality of patents filed by leading Chinese universities and the role of subsidy programs with regard to university patenting in China. Zhu, Y. X. [8] Utilizing SPSS analysis software and linear correlation analysis, this research the impact of R\&D expenditure on the number of patent applications of large countries and small countries. Research founding that, for large R\&D country, the applied research and experimental development funds positive linear relationship between patent applications and for developing countries, applied research and experimental development funds of the patent have a significant quadratic or cubic relationship. Fisch [9] provided analyses from an international perspective, examining patents at the top 300 universities worldwide. By providing a patent ranking system and an analysis of the determinants of university patenting, they enabled an international comparison not only between different countries but also between universities within countries. An empirical study addressing how applications filed by pro-se inventors fare compared to applications in which inventors were represented by patent attorneys or agents [10].

\subsection{Analysis of factors influencing the number of patent applications}

The patent system plays an important role in stimulating the economy, and it serves as an incentive for innovation by giving inventors an exclusive right to their inventions for a limited period of time. It also increases and hastens the publication of useful knowledge by requiring inventors to disclose their invention to the public [11]. On the other hand, because it must rely on imperfect information, the patent system will inevitably make mistakes. To determine how the system ought to err in cases of uncertainty and whether a given mistake is worth correcting scholars have composed a simple picture of the consequences of error in either direction [12].

Ma, T. [13]Utilizing the data based on the Zhejiang ICT industry school-enterprise cooperative application for patent in 2014 by the state intellectual property office, a weighted hypergraph based regional school-enterprise cooperative application for patent has been constructed It is concluded that Zhejiang ICT industry should further develop school-enterprise cooperative and strengthen inter-provincial school-enterprise cooperative, among which the government should play a role of policy guidance. William H.A. Johnson [14] Studied regional patent application behavior, quantity relationship between technology market and technology enterprises, through the empirical study found that market through from regional technology and assigned to the area, which ACTS as a patent application and technology of intermediaries between the number of enterprises, promote the common development of both. Ponomariov [15] investigated the effectiveness of university research centers as a Science and Technology policy mechanism, and found that nano-centers positively impact nano-patent production at universities. Policy and theoretical implications are discussed.

$\mathrm{Xu}, \mathrm{M}$. [16] researched in different types of industrial relations between patent applications and R\&D input factors, it is concluded that: low scale, high patent applications in industrial scale under the influence of R\&D personnel of full-time equivalent patent applications in the most obvious and the medium scale industry affected 
by the research and development spending is the largest. Albert G.Z. Hu [17] by using the state intellectual property office of the relevant data, studied the cause of China's patent growth, it is concluded that: the patent relationship between growth and development, labor productivity has weakened, especially for the patent for utility model. Xu, M. [18] studied the correlation between the intensity of R\&D investment and the density of regional patent applications. The research finding that: (1) In the low R\&D input area, there is a negative correlation between them. (2)In the R\&D input area, there is a non-significant positive correlation between them.(3) In the area of high R\&D investment, there is a significant positive correlation between the two. Therefore, regional differences need to be considered in the formulation of R\&D policies. Somaya [19] examined how the combination or bundling of resources influences firm-patenting performance, and found that firm-patenting output depends not only on R\&D resources, but also on the patent law expertise combined with R\&D inside the firm. Haapanen [20] investigated how the innovation expectations of public financiers are related to realized patents based on a novel data set of collaborative R\&D projects.

Byeongwoo KANG [21] Starting from the analysis of patent data, the innovation process of Huawei and ZTE in China is compared. Finally, the conclusion: ZTE's R\&D output was absorbed by Huawei, but lack of enough domestic innovators to create the output of its value interiorly, therefore suggested that the government departments to formulate relevant policies to foster more innovators to take advantage of these output to create greater value. Zheng, Y. M. [22] first with the government support, conditions of human capital, market system and the industrial structure characteristics of the four indexes indirectly reflect the innovation environment, in patent filings reflects the collaborative innovation output, then the innovation environment influence on innovation output, finally it is concluded that four indexes of innovation environment has positive influence on innovation output. Xibao Li [23] examined a number of forces that have possibly contributed to the explosive growth of Chinese patenting over the past decade, found that a larger fraction of applications is granted patent rights since the implementation of such programs, suggesting that reduction in patent application quality may not be a serious concern, unless the criteria used for patent examination have been lowered.

According to the above application for a patent for several factors affecting the finishing and other factors, this paper proposes the scientific research ability, the application process, the rule of law, the connection between colleges and enterprises, patent consciousness, rules and regulations, funds of science and technology, social economy, scientific research equipment and the government support as affects the patent application number 10 drivers. These 10 drivers are described in detail below.

The scientific research ability, scientific research ability is mainly referring to the internal teaching staff in universities, graduate students and the number and quality of scientific research team experiences, the excellent graduate team depend on the number of the masters and doctors and the source of examinee. The active research team refers to the team's internal personnel structure, relationship management, team internal incentive system and so on.

The application process, the application process mainly refers to the whole process from patent application to patent authorization by university researchers. Simple and easy operation application process is helpful to inspire the enthusiasm of an application for a patent for scientific research personnel. On the contrary, cumbersome and difficult operation application process will affect the enthusiasm of an application for a patent for scientific research personnel, and make it difficult in front of the patent application. Therefore, good patent application procedure has a great influence on patent application.

The rule of law, it mainly refers to the protection of patent right. A strict and complete legal system is conducive to safeguarding the rights of patent applicants and stimulating the enthusiasm of university researchers to apply for patents. On the contrary, the imperfect legal system and the government's neglect of infringement will lead to the loss of enthusiasm of researchers for patent applications, which will inevitably affect the number of patent applications of researchers.

The connection between colleges and enterprises, it refers to the connection and cooperative between universities and enterprises. Proper cooperative between universities and enterprises will promote college researchers to apply innovative thinking to specific industries so as to facilitate patent application. Universities have advantages in scientific and technological innovation, while enterprises have unique advantages in product transformation. Combining the advantages of both will promote scientific and technological innovation and product transformation, and at the same time contribute to the improvement of the number of college patent applications.

Patent consciousness, it mainly refers to two aspects, one of which refers to the awareness of scientific researchers applying for patents. Some studies have found that some of the scientific research achievements of universities are asleep in the middle of universities. For various reasons, university researchers do not apply for patents for their research achievements, it may be that they don't pay attention to patent applications, while others may come from universities interior. No matter what the reasons, the first step to improve the number of college patent applications is to improve the awareness of patent application. Only with the awareness of patent application can we actively apply for patent, and finally increase the number of patent applications. On the other hand, it refers 
to the degree to which all sectors of society attach importance to the application of patents. If all sectors of society attach great importance to the application of patents and maintain patents, it will inevitably lead people to actively apply for pat

Rules and regulations, it refers to the rules and regulations on patent application in universities. Good and complete patent application rules and regulations in universities are of vital importance to patent application, such as integrating the number of patent applications into the professional title assessment system, giving awards to patent application personnel, setting up patent application and maintenance fund, and holding regular training lectures on patent application. All the above rules and regulations will affect the number of patent applications of university researchers. Therefore, if universities want to increase the number of patent applications of researchers, they should formulate rules and regulations suitable for patent applications.

Science and technology funds refer to funds for scientific research activities in universities. Abundant funds will ensure that researchers have a good environment for scientific research in material terms, so that they can concentrate on scientific research and promote patent application. Therefore, universities should try their best to have enough scientific and technological funds to invest in scientific research activities and actively encourage teachers to declare various national or provincial level projects, so as to obtain necessary scientific and technological funds and promote innovation.

Social economy, it refers to current social economy development condition. Good social economy will promote the continuous cooperative between universities and enterprises to pursue higher development. Meanwhile, good economy will also promote the development of social related fields, such as the formulation and implementation of laws and regulations, which will affect the number of college patent applications.

Scientific research equipment, it refers to the equipment used by university personnel in carrying out scientific research activities. Scientific research activities carried out without certain scientific research equipment, as the saying goes " one can not make bricks without straw ", by the same token, only has first-class scientific research personnel have no complete scientific research equipment, this is difficult to carry out scientific research activities. So universities should be as much as possible provide good scientific research equipment for scientific research personnel, so as to ensure scientific research from the view of material environment, so as to promote the scientific research innovation and patent application.

Government support, it means government support for college patent applications. This is mainly reflected in the corresponding supporting policies for the cooperative between universities and enterprises, as well as the convenient policies for college patent application. In a word, an organization or individual can't develop well in the society without the support of the government. Universities should actively seek the government's support in patent application to promote patent application.

It can be seen from the above domestic and foreign studies that most of the previous studies on the amount of patent applications have focused on studying the influence of certain factors or certain factors on the amount of patent applications through statistical analysis, while less studies have focused on how the factors influencing the amount of patent applications interact with each other and affect the amount of patent applications. On the account of this, this paper, based on the research achievements of predecessors, combed the influencing factors of patent applications in the system, and focuses on the effect mechanism between various influence factors of patent applications and its influence to the application for a patent for path, on this basis proposes the corresponding management, so as to effectively improve the patent applications provide guidance, promote continuous innovation in universities.

\section{Research routes and methods}

Considering that the number of patent applications is an indicator rather than an action, this paper will select the act of patent application to explore the factors influencing it and the influencing paths of various factors on patent applications. Considering that the number of patent applications is an indicator rather than an action, this paper will select the act of patent application to explore the factors influencing it and the influencing paths of various factors on patent applications. According to the above analysis of the factors that have effect on patent applications and other influencing factors, firstly, select the application process, the rule of law, the connection between colleges and enterprises, patent consciousness, rules and regulations, funds of science and technology, social economy, scientific research equipment and the government support as the 10 factors that influence the university patent applications and then select a questionnaire survey was conducted in universities in Jiangsu province and Exploratory Factor Analysis and structural equation model to study.

\subsection{Questionnaire design and distribution}

According to the summary of existing scales and relevant theories, the questionnaire is divided into three parts: personal information, influential factors of patent application and measurement of patent application. In the influencing factors of patent application. There are two questions under the four influencing factors of legal system, scientific research equipment, application procedure and social economy. There are three questions under four 
influencing factors, including rules and regulations, patent awareness, scientific research funds and schoolenterprise relations. Government support and scientific research capacity are affected by four questions under two factors. The questionnaire adopts Likert five-point scale design method to quantify the answers to the questions in the questionnaire (Except for personal information). 1 is "strongly disagree", 2 is "strongly disagree", 3 is "generally", 4 is "agree", 5 is "strongly agree". In order to ensure the scientific nature and adaptability of the questionnaire, before the formal issuance of the questionnaire, the questionnaire was sent to relevant experts, teachers and graduate students for trial filling and revision, and finally a formal questionnaire was formed.

Because this paper selects the object of empirical analysis of universities in Jiangsu province, so in this paper, the questionnaire distributed object choice for universities in Jiangsu province of graduate students and a teacher, a questionnaire way to take the scene combined with distributed online to ensure that the number of samples can meet the needs of their statistical analysis, questionnaire issue when considering the attributes of each school at the same time, to do all kinds of universities have the investigation and analysis to achieve the integrity and authenticity of the data collection as possible.

\subsection{Research technique}

As a result of the questionnaire to collect data can't accurately reflect the actual condition of each variable, independent variable and dependent variable measuring error, and the research of this paper to deal with multiple causes and results of relationships and still contain multiple potential variables, so the paper will use the Structural Equation Model (SEM) to study the effect of an application for a patent for the influence of various factors on the patent application path. The specific process includes the following: (1)first, use Exploratory Factor Analysis (EFA) to extract public factors (latent variables) that affect 10 factors of patent application. (2)Then, CFA was used to test the relationship between each latent variable and observation variable, and the observation variable with small load coefficient was eliminated. (3) In the end, it constructs the path model of influencing factors for patent application and USES Lisre19.2 software for verification and modification, and finally obtains the load coefficient and path coefficient.

\section{Empirical analysis}

\subsection{Sample descriptive analysis}

In this survey, 350 questionnaires were actually issued, and 307 questionnaires were collected, with a recovery rate of $87.7 \%$ and a high recovery rate. It can be seen from the collected questionnaire that (1)according to the age of the subjects the majority of the respondents are over 35 years old, indicating that the respondents are mostly teachers. (2)According to the identity of the subject, there are 56 graduate students, accounting for $18.2 \%$ of the total number of samples. 71 lecturers, accounting for $23.1 \%$ of the total number of samples; 85 associate professors, accounting for $27.7 \%$ of the total number of samples. 90 professors, accounting for $29.4 \%$ of the sample. 5 other personnel, accounting for $1.6 \%$ of the total number of samples. The reasonable distribution of respondents indicates that the sample data can basically reflect the patent application situation of universities. (3)According to the study or working hours of respondents, most of them studied for 1-5 years and worked for more than 10 years, which indicates that respondents have a relatively good understanding of the internal situation of universities and are suitable for filling in this questionnaire. Regarding whether the respondent has applied for a patent or not, 283 of them indicated that they have applied for a patent, accounting for $92.2 \%$ of the total number of samples. This proportion is relatively high, indicating that the majority of respondents are quite familiar with the application process.

\subsection{Reliability and validity analysis of the questionnaire}

Reliability analysis for the questionnaire as a whole, it is concluded that the questionnaire of the whole Cronbach's $\alpha$ value is 0.792 , under normal circumstances $\alpha$ value, the higher the reliability of the questionnaire, in general, if the $\alpha>0.9$, the questionnaire reliability is very good, if $0.8<\alpha<0.9$, the questionnaire reliability is good, it is generally believed the questionnaire reliability is greater than 0.5 is reasonable, in this paper, the overall questionnaire reliability is 0.792 , close to 0.8 , so that the questionnaire has good reliability. At the same time, the Cronbach's magnitude of each influencing factor is greater than 0.6 , indicating that the reliability of each influencing factor is also better and credible.

This paper use factor analysis to analyze the structure validity of the questionnaire, in order to determine whether a questionnaire for factor analysis and need to be calculate the KMO value and the Bartlett's test of sphericity before the analysis of questionnaire, if KMO value closer to 1 indicates the questionnaire the strong correlation between the variables, suitable for factor analysis, if close to 0 indicates the questionnaire correlation is weak, the variables are not suitable for do factor analysis, it is generally believed KMO value above 0.9 suitable for factor analysis, said more than 0.8 suit to do factor analysis, said more than $0.7,0.6$ the following said don't fit, 0.5 below indicates that it is not suitable. The Bartlett's test of sphericity is that the correlation coefficient matrix 
of the original variable is the identity matrix.

Firstly, the KMO value and the Bartlett's test of sphericity values were calculated respectively by using SPSS software for the corresponding items of each influencing factor, and the significance probability of the Bartlett's test of sphericity value was 0.000 , less than 0.001 , indicating that it was suitable for Exploratory Factor Analysis within each influencing factor. At the same time, exploratory factor analysis was carried out on the corresponding items of each influencing factor respectively. The results showed that only one common factor with a characteristic value greater than 1 could be extracted from the corresponding items of each influencing factor, and the cumulative variance contribution rate of all factors was greater than $60 \%$, and the factor load of all variables on the factors obtained was greater than 0.7 . Therefore, the calculated results show that the questionnaire has good structural validity and is suitable for analysis.

According to the above analysis on the reliability and validity of the questionnaire, it can be seen that the reliability and validity of the questionnaire are better, which is suitable for the following analysis.

\subsection{Exploratory factor analysis of influencing factors}

In order to extract the latent variables in the structural equation model, this paper first randomly $1 / 3$ of the total number of samples, and exploratory factor analysis is used to extract the influence factors of public factor, the influence factors in the questionnaire with their corresponding sum of the each item, but considering the different factors affecting the design of item number is different, so after the sum calculation to complete all the factors, unify them into full marks for a 10-point scale score, it can eliminate all the factors because of the different size of item set between the score difference arising from the below do confirmatory factor analysis is based on rules.

Using exploratory factor analysis to extract the common factor of affecting factors of process is as follows: first, calculate the KMO and Bartlett's test of sphericity values of the overall questionnaire. According to the calculated the overall questionnaire KMO value is 0.863 , the Bartlett's test of sphericity is 0.000 , less than 0.001 , thus the questionnaire suitable for factor analysis, and then extract characteristic values greater than 1 factor rotation method and use the maximum variance of each variable on each factor of the load, relevant value as shown in table 1.

Table 1 exploratory factor analysis of influencing factors

\begin{tabular}{cccc}
\hline component & 1 & 2 & 3 \\
\hline the rule of law & .949 & - & - \\
the application process & .943 & - & - \\
the patent consciousness & .912 & - & - \\
the social economy & .945 & - & - \\
funds of science and technology & - & .922 & - \\
the scientific research ability & - & .916 & - \\
scientific research equipment & - & .845 & - \\
rules and regulations & - & .910 & - \\
the connection between colleges and enterprises, & - & .846 \\
the government support & - & - & .805 \\
principal component characteristic value & 3.888 & 3.461 & 1.034 \\
Contribution rate of principal component variance $(\%)$ & 38.878 & 34.606 & 10.340 \\
Contribution rate of accumulated variance of principal component $(\%)$ & 38.878 & 73.484 & 83.824 \\
\hline
\end{tabular}

It can be seen from table 1 that the factor loading of each influencing factor is greater than 0.8 , indicating that the extracted factor has a high degree of interpretation to the variable, and the cumulative variance contribution rate is $83.824 \%$, value is large, indicating that the extracted common factor is scientific and reasonable and suitable for being a latent variable in the structural equation model.

In addition, it can be seen from table 1 that factor 1 has a large load on the four influencing factors of the rule of law, the application process, the patent consciousness and the social economy. Through analysis, it can be seen that these four factors mainly reflect the external social environment of patent application, so factor 1 can be named as social environment factor. Factor 2 has a large load on the four influencing factors of funds of science and technology, the scientific research ability, scientific research equipment and rules and regulations. Through analysis, it can be seen that these four factors mainly reflect the internal situation of universities. So, factor 2 can be named as the internal environment factor of universities. Factor 3 has a large load on the two influencing factors of the connection between colleges and enterprises. Through analysis, it can be seen that these two factors mainly reflect the cooperative environment between universities and enterprises, so factor 3 can be named as the cooperative environment factor. 
4.4. Path model of factors influencing college patent application

4.4.1. Variable design and research assumptions

According to the above literature analysis and the characteristics of internal and external latent variables of the structural equation model, the variable structure of the following structural equation model is constructed in this paper, as shown in table 2 .

In order to make better use of the structural equation model to analyze the relationship between various latent variables, it is necessary to assume the relationship between variables before using Lisrel9.2 software for analysis.

The internal environment of universities includes scientific and technological funds, scientific research capacity, scientific research equipment and rules and regulations. Sufficient funds of science and technology will provide a good material guarantee for university researchers, which will help researchers concentrate on scientific research and promote patent application. Scientific research ability is the guarantee for talents in universities to do scientific research well. Only with first-class faculty and scientific research team can they have innovative subjects and promote patent application. Scientific research equipment provides a good hardware guarantee for university researchers to do scientific research well. As the saying goes, "one can't make bricks without straw ", it means the importance of hardware equipment. Rules and regulations are all kinds of systems formulated by universities to promote patent application. This paper assumes that:

H1: Internal environment has positive influence on patent application.

Table 2 variable structure

\begin{tabular}{|c|c|c|}
\hline & t variable & observational variable \\
\hline \multirow{2}{*}{ exogenous variable } & internal environment $\left(\xi_{1}\right)$ & $\begin{array}{l}\text { the scientific research ability }\left(X_{1}\right) \\
\text { funds of science and technology }\left(X_{2}\right) \\
\text { scientific research equipment }\left(X_{3}\right) \\
\text { rules and regulations }\left(X_{4}\right)\end{array}$ \\
\hline & Social environment $\left(\xi_{2}\right)$ & $\begin{array}{l}\text { the rule of law }\left(X_{5}\right) \\
\text { the application process }\left(X_{6}\right) \\
\text { the patent consciousness }\left(X_{7}\right) \\
\text { the social economy }\left(X_{8}\right)\end{array}$ \\
\hline \multirow[t]{2}{*}{ endogenous variable } & $\begin{array}{l}\text { cooperative environment } \\
\qquad\left(\eta_{1}\right)\end{array}$ & $\begin{array}{l}\text { the connection between colleges and enterprises } \\
\qquad\left(Y_{1}\right) \\
\text { the government support }\left(Y_{2}\right)\end{array}$ \\
\hline & Patent application $\left(\eta_{2}\right)$ & $\begin{array}{c}\text { patent application quantity }\left(Y_{3}\right) \\
\text { License number }\left(Y_{4}\right)\end{array}$ \\
\hline
\end{tabular}

Social environment includes the rule of law, the application process, the patent consciousness and the social economy. Good patent protection law is an important legal guarantee to promote patent application, it is the recognition and maintenance of patent right, and it is also a strong support to scientific researchers' patent application. The application process mainly refers to the time and process that university researchers have gone through from patent application to patent authorization. Obviously, simple, easy to operate and fast patent application process will be conducive to stimulating the enthusiasm of university researchers for patent application and will frustrate their enthusiasm and make people sigh in the face of patent application. Patent consciousness mainly refers to the awareness of patent application from all walks of life and the importance of patent transformation. As the saying goes, "material determines consciousness". Only when people from all walks of life attach importance to the application of patent can they promote the application of patent. In the same way, only when all sectors of society attach importance to the transformation of patents can they give full play to their due value, which in turn will promote the application of patents. A good social economy will promote the development of all walks of life in society. Meanwhile, in order to seek better development, all walks of life may promote the transformation of patents to achieve further innovation, which can to a certain extent increase the popularity of social patent application and promote patent application. This paper assumes that:

$\boldsymbol{H} 2$ : Social environment has positive influence on patent application.

The cooperative environment includes the connection between colleges and enterprises and government support. The connection between colleges and enterprises mainly include the declaration of national or provincial level projects, cooperative participation in related projects and so on. Universities generally have advantages in scientific and technological innovation, while enterprises have advantages in the transformation of results. If the two cooperate, they will be able to combine scientific and technological innovation with the transformation of results organically, thus promoting patent application and social progress. Government support mainly refers to 
the government's support in inter-school project cooperative and in patent application. No individual or organization can develop well in the society without certain government support. For example, a positive and favorable policy to promote industry-university-research cooperative will be conducive to school-enterprise cooperative, thus promoting patent application and achievement transformation. This paper assumes that:

H3 : Cooperative environment has positive influence on patent application.

The four factors contained in the internal universities environment are conducive to forming the forces of internal scientific research in universities, which can promote the cooperative between universities and enterprises outside the university and obtain government support. For example, good scientific research equipment in universities is one of its major advantages. Enterprises often worry about the shortage of scientific research equipment when engaging in scientific research activities. Excellent faculty and research teams will also promote cooperative between universities and enterprises, provide abundant personnel guarantee for cooperative between universities and enterprises, and ultimately seek better development of both sides. In addition, the excellent internal environment of universities will also greatly enhance the comprehensive strength of the university, and thus obtain more government support, including the support for inter-school cooperative and patent application. This paper assumes that:

H4: The internal environment has positive influence on the cooperative environment.

The well development of various factors in the social environment will help to form a stable and harmonious external environment for patent application. On this basis, all parties will seek for complementary advantages, strengthen cooperative and develop together. For example, a good rule of law will provide a legal guarantee for the patent application of the cooperative between school and enterprise so as to promote the continuous cooperative and development between the cooperative between school and enterprise. The simple, easy to operate and short time patent application procedure also provides convenience for inter-school patent application and promotes the two sides to strengthen cooperative and seek common development. The awareness of patent will also promote the active cooperative between the university and enterprises and promote patent application and patent transformation. A good economic environment will encourage universities and enterprises to continuously seek external cooperative to complement each other's advantages and finally promote the common development of both sides. In addition, a stable and harmonious external environment for patent application will help the government to provide more support policies for inter-school cooperative and college patent application. For example, the rapid economic development will increase the government's financial revenue. This paper assumes that:

H5 : Social environment has positive influence on cooperative environment

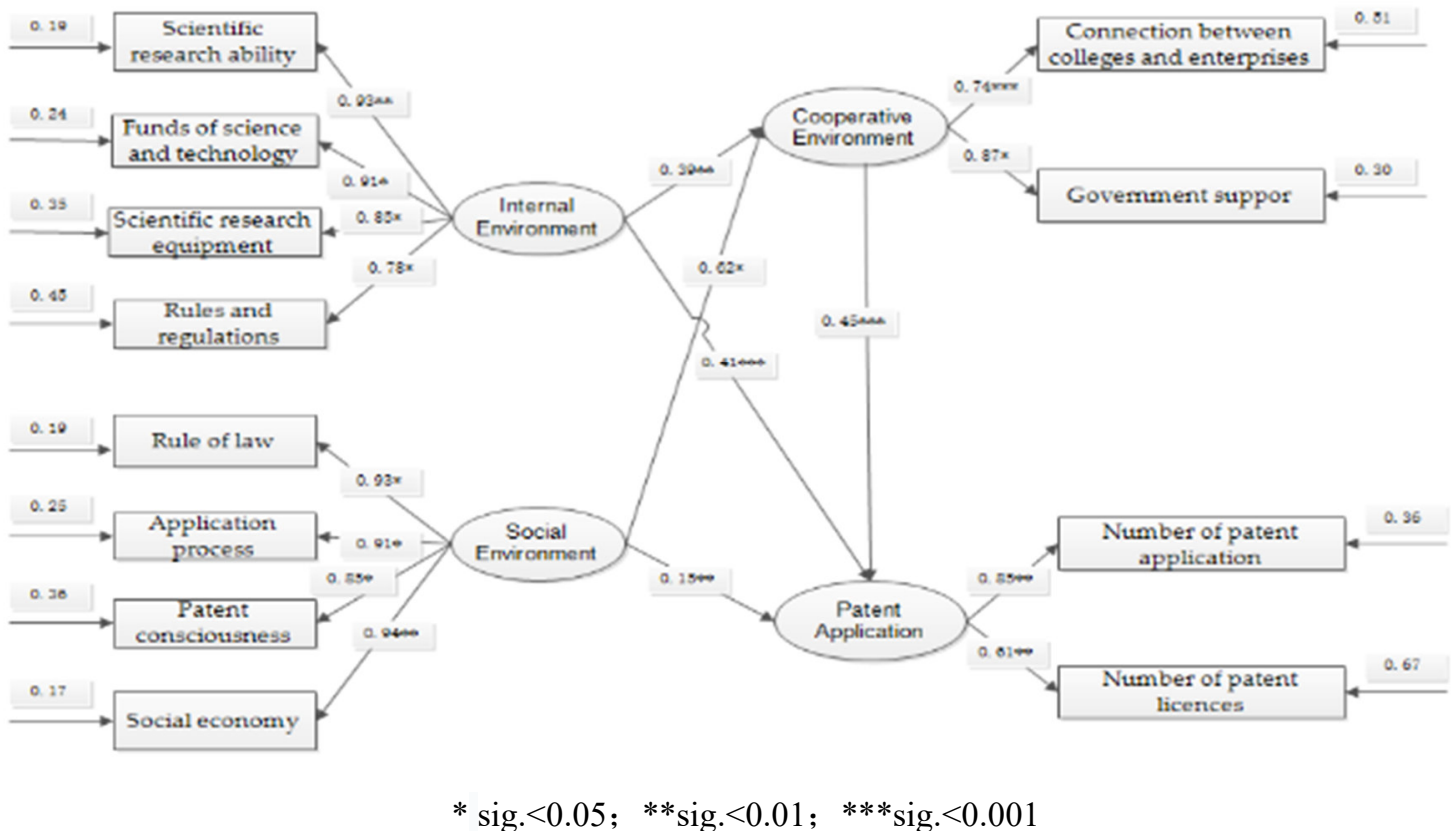

4.4.2. Model construction and testing

figure 1 Model on Influential Factors upon Universities' Patent

On the basis of variable design and research hypothesis, this paper first uses Lisrel9.2 software to conduct confirmatory factor analysis, and constructs the relationship model between latent variables and observation variables. Through analysis, it is concluded that the load coefficient between each latent variable and observation variable is greater than 0.6 , indicating that each observation variable has a good subordinate relationship with the 
latent variable. Then, the software is used to verify and modify the path model of the factors influencing college patent application. The correction process is carried out with the help of $t$ value and correction index. The final path coefficient after modification is shown in figure 1.

The fitness index of the model is to evaluate the fit between the model diagram of the assumed path analysis and the collected data, and the degree to which the model diagram of the hypothesis is consistent with the actual data. In this paper, two absolute fitness indicators, AGFI and GFI, are selected for reference in relevant literature [24]. The values of these two indicators are between 0 and 1 . The higher the value is, the higher the adaptability of the hypothesis model is. PGFI is a simple fitness index, which can be set at a value greater than 0.5 . CFI is obtained from the comparison between the fitting of the set model and the fitting of the independent model. In the process of model fitting, the non-central distribution and non-central parameters are applied, and the value is between 0 and 1 . The specific evaluation indicators of the model are shown in table 3 .

Table 3 evaluation indicators

\begin{tabular}{ccc}
\hline indicator & Adapter standard & The fitting value of this model \\
\hline GFI & $>0.90$ above & 0.91 \\
AGFI & $>0.90$ above & 0.88 \\
CFI & $>0.90$ above & 0.92 \\
PGFI & $>0.50$ above & 0.53 \\
\hline
\end{tabular}

From the evaluation index of the model, except the $A G F I$ value is slightly less than the standard value of adaptation, the path model constructed in this paper satisfies the standard value, indicating that the value obtained by the model is statistically acceptable.

It can be seen from table 4 that hypothesis $\mathrm{H} 1 \sim \mathrm{H} 5$ is adopted, indicating that the internal environment, social environment and cooperative environment of universities all have a positive impact on the patent application of universities, and the internal environment and social environment of universities also have a positive impact on the cooperative environment. In addition, the path model of influencing factors for college patent application can be used to obtain the effects of various influencing factors on college patent application, as shown in table 5 .

Table 4 hypothesis testing and path coefficient

\begin{tabular}{|c|c|c|c|c|}
\hline $\begin{array}{l}\text { Assume that the } \\
\text { variable }\end{array}$ & Route description & $\begin{array}{l}\text { Standardized path } \\
\text { coefficient }\end{array}$ & $\begin{array}{l}\text { Value } \\
\text { P }\end{array}$ & $\begin{array}{l}\text { Inspection } \\
\text { result }\end{array}$ \\
\hline $\mathrm{H} 1$ & $\begin{array}{c}\text { Internal environment-- }>\text { Patent } \\
\text { application }\end{array}$ & $0.41(* * *)$ & $<0.05$ & Obviously \\
\hline $\mathrm{H} 2$ & $\begin{array}{c}\text { Social environment-- }>\text { Patent } \\
\text { application }\end{array}$ & $0.15(* *)$ & $<0.05$ & Obviously \\
\hline $\mathrm{H} 3$ & $\begin{array}{c}\text { Cooperative environment }-->\text { Patent } \\
\text { application }\end{array}$ & $0.45(* * *)$ & $<0.05$ & Obviously \\
\hline $\mathrm{H} 4$ & $\begin{array}{l}\text { Internal environment --> } \\
\text { Cooperative environment }\end{array}$ & $0.39(* *)$ & $<0.05$ & Obviously \\
\hline H5 & $\begin{array}{c}\text { Social environment-- }>\text { Cooperative } \\
\text { environment }\end{array}$ & $0.62(*)$ & $<0.05$ & Obviously \\
\hline
\end{tabular}

Table 5 the effect between various influencing factors and patent application

\begin{tabular}{cccccccccc}
\hline \multirow{2}{*}{ effect } & \multicolumn{3}{c}{ Internal environment } & \multicolumn{3}{c}{ Social environment } & \multicolumn{3}{c}{ Cooperative environment } \\
& direct & indirect & total & direct & indirect & total & direct & indirect & total \\
\hline $\begin{array}{c}\text { Cooperative environment } \\
\text { Patent application }\end{array}$ & 0.39 & - & 0.39 & 0.62 & - & 0.62 & - & - & - \\
\hline
\end{tabular}

It can be seen from table 5 that the internal environment has the largest effect on college patent application, with the total effect of 0.59 , of which the direct effect is 0.41 and the indirect effect is 0.18 . The total effect of cooperative environment and social environment on college patent application is not much different, which is 0.45 and 0.43 respectively. The direct influence of social environment on patent application is 0.15 , and the indirect influence is 0.28 , indicating that the influence of social environment on patent application is mainly indirect effect, which indirectly affects college patent application by influencing the cooperative environment. The effect of cooperative environment on college patent application is 0.45 , and the effect is high.

\section{Conclusion and suggestion}

In this paper, by constructing the patent application path factor model to explore the relationships between various factors and their impact on an application for a patent for path, the results show that the influence factors of the internal environment, social environment, the cooperative environment all have positive effects on university patent application and the internal environment and social environment also has a positive effect on the 
environment cooperation, hypothesis $\mathrm{H} 1 \sim \mathrm{H} 5$ all through.

Based on the above conclusions, this paper puts forward the following Suggestions to increase the number of college patent applications in Jiangsu province of China:

1) We will vigorously foster a favorable internal environment for universities.

The internal environment of universities can not only directly influence the patent application of universities, but also indirectly influence the patent application by influencing the cooperative environment. Moreover, for Jiangsu province, the internal environment of universities has the biggest impact on the patent application of universities. Therefore, it is very important for universities in Jiangsu province to build a good internal environment. To build a good internal environment needs from within the scientific research ability, scientific research funds in universities, scientific research equipment, and the rules and regulations, this includes organizing excellent scientific research team, get plenty of scientific research funds, equipment, advanced scientific research equipment, and set to the rules and regulations of an application for a patent for the broad masses of teachers and students, and so on, through these measures will foster the good internal environment in universities, thus is advantageous to the application for a patent for universities.

2) Building a favorable social environment for college patent application

The social environment influences both the cooperative environment and the patent application, and the social environment influences the patent application mainly by influencing the cooperative environment. In order to effectively increase the number of college patent applications in Jiangsu province, Jiangsu province and relevant national departments should do the following work. (1)strengthen the construction of patent laws and regulations, increase government support for patent applications, and allocate special funds to improve patent laws and regulations. (2) Accelerate the speed of patent examination and approval, reduce the time from application to authorization of patents, so as to improve the enthusiasm of university researchers to apply for patents(3)Raise the awareness of patent in the whole society, hold regular patent technology exchange and achievement exhibition, and give lectures related to patent application and transformation in universities and enterprises. (4) A good economic environment will be conducive to inter-school cooperation to promote innovation and generate more patents. Therefore, we need to "roll up our sleeves and work hard".

3 ) Create a harmonious environment for school-enterprise cooperation

The operating environment has a great impact on college patent application and is affected by the internal environment and social environment of colleges and universities. Therefore, universities and society in Jiangsu province should actively cultivate a good cooperative environment, so as to better play the role of internal environment and social environment. A good cooperation environment is conducive to the full play of the advantages of universities and enterprises, so as to promote college patent application. Colleges and universities should encourage teachers to cooperate with enterprises more, deeply understand the problems encountered in the actual operation of enterprises and take problems as the orientation. Both sides should actively explore and cooperate to find solutions, which may promote college patent application in the process of solving problems. The government of Jiangsu province should formulate relevant policies to promote the development of the cooperative environment, including: (1)Encouraging enterprises, universities and research institutes to actively establish highlevel and high-level strategic alliances on industrial and technological innovation, become the leading and core members of industrial and regional alliances, and actively promote innovation. (2)Circulating a related patent application fund to reduce the related expenses of inter-university patent application and promote patent application. (3)Encouraging all parties in universities and enterprises to actively explore the mechanism of sharing benefits and risks in the process of cooperation, so as to promote better and more sustainable development of interschool cooperation.

Future research will focus on the influential factors of patent applications for companies or specific industries. And establish a more complete verification and correction model to make the conclusion more practical.

\section{References}

[1]Xu S , Wang Z J , Zhao H F . Patent Innovation Factors Evolution Based on P-SVM and GCCA[J]. Applied Mechanics and Materials, 2010, 39:247-252.

[2]Tinnemann P, O” zbay J, Saint VA, Willich SN (2010) Patenting of University and Non-University Public Research Organisations in Germany: Evidence from Patent Applications for Medical Research Results. PLoS ONE 5(11): e14059. doi:10.1371/journal.pone.0014059

[3]Zhang Q H, Luo J W. Analysis on the influence of the patent funding policy of Shanghai for the figure of patent application[J]. Studies in Science of Science, 2009, 27(5):682-685.

[4]Eduardo Fé. (2013). Count data stochastic frontier models, with an application to the patents-R\&D relationship. Journal of Productivity Analysis, 39(3), 271-284.

[5]Christian Fisch,Philipp Sandner, Lukas Regner. The value of Chinese patents: An empirical investigation of citation lags[J]. China Economic Review,2017,45:22-34. 
[6]Dang, J., \& Motohashi, K. (2015). Patent statistics: a good indicator for innovation in china? patent subsidy program impacts on patent quality. China Economic Review, 35, 137-155.

[7]Fisch, C., Block, J. H., \& Sandner, P. G. (2016). Chinese university patents: Quantity, quality, and the role of subsidy programs. Journal of Technology Transfer, 41(1),60-84.

[8]Zhu, Y. X., \& Fang, S. (2007). Relationship between the numbers of patents applying and expenditure on three R\&D activities. Studies in Science of Science,25(01):123-127.

[9]Fisch, C., Hassel, T., Sandner, P. G., \& Block, J. H. (2015). University patenting: A comparison of 300 leading universities worldwide. Journal of Technology Transfer, 40(2), 318-345.

[10]Gaudry, Kate S. (2012)The Lone Inventor: Low Success Rates and Common Errors Associated with Pro-Se Patent Applications. PLoS ONE 7(3): e33141

[11]Elliott G. Basics of US patents and the patent system. AAPS J. 2007;9(3):E317-24.

[12]Yelderman, S. (2017). The value of accuracy in the patent system. University of Chicago Law Review, 2017,84(03): 1217-1284.

[13]Ma, T., Guo, J., \& School, B. (2016). Hypernetwork model on regional-level university-enterprise cooperation for applying patent based on weighted hypergraph: a case of ICT industry in Zhejiang. Technology Economics,35(12):76-82.

[14]William H.A. Johnson, Qing Liu. Patenting and the role of technology markets in regional innovation in China: An empirical analysis[J]. Journal of High Technology Management Research,2011,22(01):14-25.

[15]Ponomariov, B. (2013). Government-sponsored university-industry collaboration and the production of nanotechnology patents in US universities. Journal of Technology Transfer, 38(06): 749-767.

[16]Ming, X. U. (2016). Research on the elasticity relationship between patent application and R\&D input factors: the empirical study on the panel data of thirty-six industries. Science of Science \& Management of $S \&$ T.,37(01):30-37.

[17]Albert G.Z. Hua, Peng Zhangb, Lijing Zhao. China as number one? Evidence from China's most recent patenting surge[J]. Journal of Development Economics,2017,124:107-119.

[18]Xu, M. (2015). An empirical research on the correlation between $r \& d$ investment intensity and regional patent application density. Journal of Intelligence,34(07):100-105.

[19]Somaya, D., Williamson, I. O., \& Zhang, X. (2007). Combining patent law expertise with r\&d for patenting performance. Organization Science, 18(6), 922-937.

[20]Haapanen, Mika; Lenihan, Helena; Tokila, Anu. (2017). Innovation Expectations and Patenting in Private and Public R\&D Projects. Growth and Change,48(4):744-768

[21]Byeongwoo KANG. The innovation process of Huawei and ZTE: Patent data analysis[J]. China Economic Review,2015,36:378-393.

[22]Zheng, Y., \& Zhang, Y. (2014). Empirical analysis on effect of innovative environment on university-industry collaborative innovation. Technology Economics, 33(05):46-50.

[23]Xibao Li. Behind the recent surge of Chinese patenting: An institutional view[J].Research Policy,2012,41(01):236-249.

[24]Li, Y., Wang, Y., Hu, Y., \& Management, S. O. (2015). An analysis on factors influencing technology innovation in strategic emerging industries based on the structural equation model. Science Research Management, 49(3), 337-350. 